\title{
Resignificando la mirada desde el pensamiento complejo mediante la apreciación estética de «Melancolía I»
}

\author{
ANA JIMÉNEZ MURCIA* \\ Corporación Universitaria Minuto de Dios - Colombia \\ Recibido el 02-06-19; primera evaluación el 05-05-20; \\ segunda evaluación el 08-07-20; aceptado el 17-07-20
}

\section{RESUMeN}

Esta investigación ha permitido generar una propuesta de apreciación de la obra «Melancolía I» de Alberto Durero, fundamentada en los siete principios teóricos de Edgar Morín en referencia a su propuesta del pensamiento complejo. Para ello, se propuso una guía de interpretación pedagógica que favoreció el análisis y la apreciación del trabajo mencionado. Con respecto a la naturaleza de la investigación, el método es de carácter cualitativo hermenéutico, mediante una relación dialógica entre artista, profesores y contempladores. Los resultados indican que los observadores relacionaron elementos fundamentales del grabado, conectando símbolos del Renacimiento con su mundo interior. Producto de esta investigación, se generó una propuesta de interpretación de una pieza estética que contribuyó al mejoramiento de la enseńanza de apreciación del arte.

Palabras clave: «Melancolía I», educación artística, arte, pensamiento complejo, estética.

\footnotetext{
* Magíster en Investigación Integrativa con enfoque en Apreciación del Arte. Especialista y licenciada en Educación Artística, con una experiencia de diez ańos en el sector educativo. Doctoranda en Ciencias de la Educación, modalidad virtual en la Universidad Arturo Prat, Chile. Docente de la Corporación Universitaria Minuto de Dios, en la Facultad de Educación. Correos electrónicos: ana.jimenezm@ uniminuto.edu y anagracejimenez@hotmail.com. https://orcid.org/0000-0002-9757-6537
} 


\section{Resignifying the gaze from the complex thinking through the aesthetic appreciation of «Melancolía I»}

\section{Abstract}

The investigation has allowed the formulation of a proposal for the appreciation of the aesthetic piece «Melancholy I» by Albrecht Dürer, grounded on the seven theoretical principles of Edgar Morín related to his conception of Complex Thought. To this end, I proposed a guide for pedagogical interpretation, which favored the analysis and appreciation of the work mentioned. Concerning the nature of the investigation, the method is of a hermeneutic qualitative character by means of a dialogical relationship between artist, teachers and contemplators. The results indicated that viewers relate to fundamental elements of and the engraving by connecting symbols of the Renaissance with their inner world. As a product of this research, a method was proposed for the interpretation of aesthetic pieces that contributed to the improvement of the teaching of the artistic appreciation.

Keywords: «Melancholy I», artistic education, art, complex thinking, aesthetics.

\section{Ressignificando o olhar do pensamento complexo através da apreciaçáo estética da «Melancolia I»}

\section{RESUMo}

A pesquisa gerou uma proposta de apreciação do trabalho «Melancolía I» de Alberto Durero, baseada nos sete princípios teóricos de Edgar Morín, referindo-se à sua proposta de pensamento complexo. Para isso, foi proposto um guia de interpretaçáo pedagógica, que favoreceu a análise e apreciação do trabalho mencionado. Quanto à natureza da pesquisa, o método é de natureza hermenêutica qualitativa, por meio de uma relação dialógica entre artista, professores e contempladores. Os resultados indicam que os observadores relacionaram elementos fundamentais da gravura, conectando símbolos do Renascimento com seu mundo interior. Como resultado desta pesquisa, foi gerada uma proposta para a interpretação de uma peça estética, o que contribuiu para melhorar o ensino da apreciação da arte.

Palavras-chave: «Melancolia I», educação artística, arte, pensamento complexo, estética. 


\section{INTRODUCCIÓN}

En primer lugar, cabe resaltar que esta investigación se sustenta a partir de la tesis de maestría titulada "Pensamiento complejo y apreciación estética en la obra "Melancolía I" (ver figura 1) de Alberto Durero" (Jiménez, 2016) desarrollada por la autora de este documento, quien decidió acercar este tema al ámbito educativo.

El interés de esta investigación es generar tanto en el profesor como en los estudiantes u observadores una manera diferente de comprender una obra de arte centrada más allá de los campos semióticos e historiográficos. La obra puede ser abordada mediante los siete principios del pensamiento complejo de Edgar Morin (2001), que serán expuestos más adelante, y los aspectos epistemológicos como el lingüístico, el histórico, el cultural y el subjetivo, que incluyen elementos iconológicos e iconográficos. Los primeros hacen referencia al «objeto mismo, su origen, las obras literarias de donde se ha inspirado y procesos por los que ha llegado a tener determinada interpretación» (Velázquez, 2012); y los segundos son entendidos como «el contenido temático o significado de las obras de arte» (Panofsky, 2018, p. 41). Con estos conceptos el docente de educación artística podrá generar una nueva manera de pensar su quehacer metodológico y pedagógico que contribuya a ampliar las perspectivas de análisis de una obra de arte y los elementos presentes en la misma.

Por consiguiente, los conceptos anteriormente mencionados abrirían el espacio a las siguientes preguntas: ¿cómo el profesor puede transmitir su comprensión de una pieza estética a quienes puedan interesarse en el entendimiento de una obra de arte como, por ejemplo "Melancolía I» de Alberto Durero, que ha intrigado a los amantes del Renacimiento desde 1514?

Además, para los contempladores también se platearon preguntas como: ¿qué elementos le permitirían al observador entender de una mejor manera esta pieza artística?, ¿̇e qué manera el observador puede identificar los índices e indicios que le ayudarán a comprender mejor una determinada obra de arte, ampliando sus conocimientos sin que se pierda la percepción subjetiva de una determinada pieza?

Por consiguiente, este documento busca sentar las bases para la generación de un instrumento pedagógico que conecte los fundamentos del pensamiento complejo de Morin (2001), con diversas premisas epistemológicas con el propósito de ayudar a cualquier docente o académico interesado en ampliar su interpretación de la obra "Melancolía I» de Alberto Durero, basándose en una red de interrelaciones que le permitan al sujeto observador, sea este 
un estudiante, o solo alguien interesado en mejorar sus conocimientos sobre el mundo del arte. De igual manera se pretende entretejer los distintos saberes implícitos que hacen parte fundamental de este grabado, e incluso abrir la puerta para que esta herramienta pueda ser usada en el análisis de otras piezas estéticas de tiempos y lugares totalmente diversos.

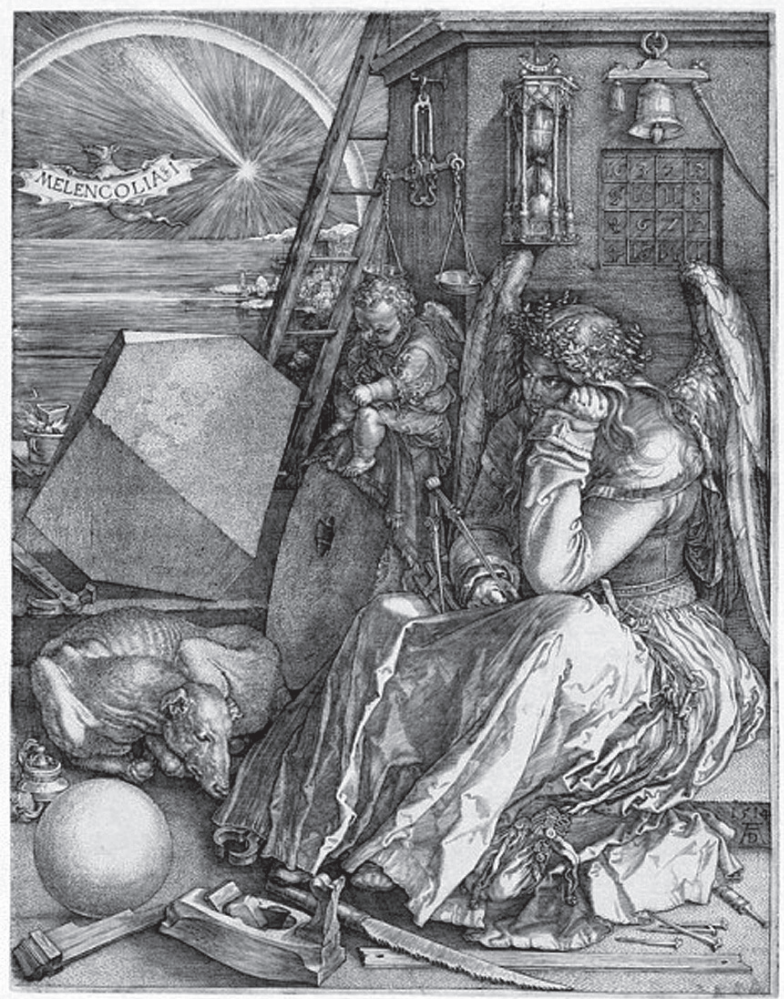

Figura 1. Durero, A. (1514). Melancolía I

\section{MarCo TEÓRICO}

\subsection{Apreciaciones iniciales sobre el contexto de la obra «Melancolía I» como apoyo a la enseñanza artística}

Al contemplar una obra de arte y apoyar los procesos de formación de la mirada estética, se requiere analizar múltiples perspectivas que acerquen al docente como sujeto investigador de una manera más profunda a los diferentes 
componentes de una obra de arte, con el fin de motivar la elaboración de una guía pedagógica interpretativa que a través de información conceptualizada haga un puente entre diferentes tipos de observadores, quienes puedan apoyar sus interpretaciones con distintas referenciaciones que enriquezcan la primera idea que se hace un observador al apreciar una obra estética y le ayuden a expandir su visión sobre el proceso de significación de una pieza de arte.

Para ello, el docente necesita realizar una investigación tanto de fuentes actualizadas como de referencias históricas relevantes que permitan entender esta obra desde sus raíces históricas, científicas, culturales y artísticas, para que pueda ampliar sus formas de análisis y considerar el conocimiento como una fuente interconectada de saberes que se entrelacen, y para que otros desarrollen nuevas formas de comprensión que en su momento no habían sido puestas en consideración.

En primer lugar, es importante comprender la noción de melancolía a partir de referencias que permitan construir un panorama que abarque desde sus primeras nociones hasta el referente estético abordado por Durero.

Durante la Edad Media y el Renacimiento, los médicos de la época fundamentaban su quehacer profesional a partir de la teoría de los humores, proveniente de la Escuela de Cos, en la Antigua Grecia, especialmente desarrollada por Hipócrates, (460-370 a.c), quien afirmaba que las afectaciones del cuerpo humano provenían del desbalance de cuatro sustancias: la sangre, la flema, la bilis amarilla y la bilis negra. Más adelante, la teoría de los humores sería retomada por el medico Romano Galeno (130-200 a.c), quien asociaría a su vez estas sustancias con los elementos de la naturaleza, es decir, la sangre con el aire, la flema con el agua, la bilis amarilla con el fuego y por último, la bilis negra con la tierra. "Estos elementos primarios entraban en el cuerpo a través de los alimentos, que se procesaban en el estómago para después pasar al torrente sanguíneo» (Bielewicz, Górniak y Rejdak, 2017, p. 90).

Por consiguiente, muchas enfermedades eran explicadas mediante esta teoría, incluyendo la melancolía, que era vista como una falencia causada por la excesiva acumulación de la bilis negra en el cuerpo. Estaba influenciada por la concepción astrológica del Planeta Saturno, que le daba al temperamento de la persona afectada un carácter frío y seco, emulando la tierra misma.

Con estas primeras referencias, el docente investigador comienza a integrar a su trabajo de construcción de una guía pedagógica interpretativa un conocimiento sobre la influencia de la medicina en la obra.

No obstante, para darle un carácter aún más holístico a sus indagaciones, es necesario aproximarse a autores que trascendían las nociones de melancolía como una afectación médica. Para llevar esta concepción al terreno 
de su influencia en la creatividad humana es preciso referenciar a filósofos y escritores como Aristóteles, quienes lograron darle una conceptualización diferente, asociando la melancolía a la genialidad del creador. «En Aristóteles, lo melancólico es, por lo tanto, un don natural y fisiológico, que determina un comportamiento singular y cualidades intelectuales excepcionales, ya se trate de la vocación heroica o política, o bien del género poético o filosófico» (Muller, 2002, p. 39).

Posteriormente, durante el Renacimiento, autores como el médico alemán Cornelio Agripa (1435-1535) atribuirían la melancolía a la relación intrínseca que ha tenido el individuo con los cuerpos celestes. Es así que, en su libro Filosofía oculta, él mencionaría que «los signos de Saturno contribuyen a la tristeza y la melancolía; los de Júpiter a la alegría y los honores» (Agrippa, 2005, p. 34).

Asimismo, el filósofo italiano Marsilio Ficino (1433-1499) ampliaría la noción de melancolía mencionada por Agripa para denotar que esta influencia astral tiene como una ventaja particular estimular el carácter creativo y filosófico del creador, para llevarlo hacia nuevas direcciones donde según Ficino (citada por Noel, 2014):

Fomento una imagen de Saturno que reflejaba sus aspectos sobresalientes: por un lado, el malvado y triste; por el otro, el profundamente pensativo. Reconociendo ambos, acentúa claramente el segundo aspecto y, de esta manera, vincula el astro de la contemplación sublime con la genialidad humana. (p. 182)

Por lo tanto, estas dos definiciones permiten avanzar hacia nuevas direcciones que dejarían atrás el concepto de melancolía como un fenómeno meramente corporal o fisiológico. Todo es con el fin de mostrarla como la intrínseca interrelación entre el individuo con los elementos del mundo natural que le rodea, en busca de nuevas maneras de expandir la imaginación creadora, haciendo que las relaciones humanas se conviertan en bases para la construcción de una conexión entre el mundo mítico y el espiritual. Estas deberían producir una interacción entre las emociones humanas y los deseos divinos, que serían los elementos coyunturales que inspirarían a Durero a lo largo de la elaboración del grabado "Melancolía I». «La melancolía deja de ser una enfermedad que se trata de ocultar, para pasar a ser una extraordinaria y sublime actividad intelectual» (Gonida, 2002, p. 37).

Esta confrontación entre la melancolía como una dolencia corporal y a su vez como una fuerza creadora es la base de la creación del grabado "Melancolía I», donde los personajes del mismo plantearían este dilema 
intelectual, especialmente en su figura principal que hace referencia a una condición anímica atormentada pero a la vez inspiradora. Allí el ángel con su gesto compungido - pero a la vez reflexivo-, expresa los dilemas que tiene el autor sobre su capacidad creadora, la forma en que su condición de artistaartesano es catalogada por su sociedad como algo poco benigno y la manera en la cual su talento es el camino para alcanzar la divinidad como individuo, pero siempre bajo una instancia espiritual y mística. Por ende:

Durero transforma la perspectiva del grabado en el espacio de un geómetra y de un artista de genio que busca las justas proporciones estéticas. El arte de la medida es entonces una especie de propedéutica para el pintor enamorado de las formas, las líneas y las curvas geométricas. (Constantinescu, 2011, p. 5)

Por consiguiente, un docente no solo debe concentrarse en los aspectos generales de una obra, sino también (como en el caso de la obra «Melancolía I»), generar una interpretación más holística de la pieza artística, donde se puedan usar las ciencias puras como otro elemento de correlación que arroje nuevas luces frente a las posibilidades que tiene este grabado de ser analizado.

De la misma madera, el deseo de conocer más sobre el autor de esta obra y las diferentes inspiraciones que lo llevaron a la construcción de su pieza estética puede ser una base para que los estudiantes también desarrollen múltiples herramientas cognoscitivas de diferentes orígenes, para gestar un entendimiento más detallado y enriquecedor de todos los componentes significativos que contiene este grabado.

Una herramienta que contribuye a lograr ese análisis integral y fluido de diferentes elementos académicos, estéticos e incluso emocionales para lograr la comprensión de cualquier trabajo de carácter artístico, es la teoría del pensamiento complejo desarrollada por Edgar Morin (citada por Torrealba, 2009), que se define como un «tejido de eventos, acciones, interacciones, retroacciones, determinaciones, azares que constituyen nuestro mundo fenoménico» (p. 171). Esta se convierte en el apoyo fundamental tanto para educadores, educandos, amantes del arte y críticos de esta área en general, para mejorar aún más los análisis existentes sobre la labor estética de un autor y aplicar estas ideas, en beneficio de ampliar los limites hasta ahora existentes de la comprensión estética de una obra, llegando a más públicos e incluso aplicándola como una nueva forma de enseńar los elementos de este grabado no como fragmentos enciclopédicos, sino como nodos interconectados que unen al autor, su tiempo, su obra y sus elementos en un universo interrelacionado de ideas. 


\subsection{El pensamiento complejo como una herramienta para la articulación y comprensión de una pieza estética}

Teniendo en cuenta la idea expresada anteriormente sobre la concepción teórica del pensamiento complejo planteado por Edgar Morin, es posible entender una pieza artística como una correlación integral de elementos que se entrelazan para producir una labor transdisciplinar, que además de identificar las intersecciones existentes en un trabajo artístico, permite reunir diferentes fuentes de saber puro, humano y social entre otros, para motivar la edificación de una nueva interpretación de las realidades latentes tanto en el mundo físico, como en la concepción artística que puede surgir en la mente humana.

Gracias a esto, «el pensamiento complejo integra lo más posible los modos simplificadores de pensar, pero rechaza las consecuencias mutilantes, reduccionistas, unidimensionalizantes y finalmente cegadoras de una simplificación que se toma por reflejo de aquello que hubiere de real en la realidad» (Morin, 2001, p. 22).

A partir de las nociones explicadas anteriormente, el paradigma del pensamiento complejo se convierte en una herramienta factible para elaborar una apreciación de la obra de arte, donde se interconectan e interrelacionan la ciencia, el arte y el individuo, para encontrar una nueva manera de explicar los elementos que forman una pieza estética como un elemento aglutinador de la creatividad humana, ya que «tanto el artista como el científico experimentan el acto creativo en relación con su cualidad estética. Ambos ejecutan una obra; cada uno utiliza los medios y los lenguajes propios que su quehacer intelectual requiere» (Barbosa, 2018, p. 146).

Por lo tanto, la teoría del pensamiento complejo de Morin (2001) llegaría a ser la más apropiada, para analizar una pieza estética tan interdisciplinar en su creación como lo es el grabado «Melancolía I» de Alberto Durero, ya que además de su iconografía e iconología, permite que tanto el profesor como el observador se sumerjan a la comprensión de las ciencias fácticas implícitas en su creación, así como de los componentes artísticos que permitieron la gestación de este trabajo estético del renacimiento, el cual, posee referencias directas a elementos propios de la ciencia, la matemática entre otras áreas del saber que enlazan en su conjunto inquietudes que requieren ir más allá de la apreciación estética, para llegar a una interpretación más incluyente a través de perspectivas provenientes de diferentes disciplinas del conocimiento humano.

Adicionalmente, para acercarse a la apreciación de la obra mencionada se requiere ampliar el horizonte de la obra misma dentro de una relación dialógica entre la pieza, el creador y el observador, entendiendo que el sujeto creador 
fue un ser holístico inmerso dentro ciertas circunstancias, interés, dudas e incertidumbres del conocimiento en su tiempo, y que el observador, aunque distante temporalmente, se iría integrando con él y con la complejidad que los sucumbe a ambos dentro de las posibles concepciones de la humanidad sobre la existencia de la vida, lo cual permite un acercamiento y una reflexión común desde posibilidades de comprensión e interpretaciones diferentes. «Solo puedo comprender aquello de lo que me hago parte: cuando el sujeto que busca se integra y se funde con el objeto buscado" (Max-Neff, 2004, p. 19).

De esta manera, cuando se habla de lo complejo en el individuo, se hace referencia a un ser con la capacidad de reflexionar de lo que aprende, revalorando, cuestionando e incluso reinterpretando o analizando dentro de sus propios parámetros la realidad que lo rodea, es decir que desde la perspectiva de Morín, se plantea que el sujeto pueda integrar las ciencias y las humanidades donde la «rearticulación nos permite al mismo tiempo contextualizar correctamente, reflexionar e intentar integrar nuestro saber con la vida» (Morín, 2000, p. 70) utilizando tanto el conocimiento aprendido en los entornos académicos o sociales como de las apreciaciones individuales.

Bajo esta premisa, la interacción entre el sujeto y los diferentes saberes se convierte en el fundamento para construir la interrelación de diferentes conocimientos que le ayudan a construir su visión actual de lo que se desea referenciar, en este caso la pieza estética que se convierte en el puente para que el sujeto no solo vea obras de arte como piezas invaluables de la historia del arte sino también como elementos interconectados con muchos saberes implícitos y explícitos provenientes de una interdisciplinariedad incluyente en su individualidad.

Sin embargo, para que la obra de arte permee el paso del tiempo y pueda tener una identidad dentro del imaginario del sujeto como individuo y como parte de un colectivo requiere un divulgador, alguien que lleve el legado de los maestros y autores más allá de su presencia en museos para hacerlos parte del diario ahí donde educadores y guías entran en escena para que el sentido o el contenido de una pieza estética se convierta en un movilizador de la expresión personal, un referente a un momento histórico o social, y a su vez, sin importar el espacio o el tiempo, haga de cada trabajo estético un puente entre mundos distantes, donde de manera interactiva se pueda comprender el sentir de una época o de una tendencia en particular, ya que la educación artística:

Favorece la perspicacia de un modo informado. Tales estrategias que le son propias, favorecen la investigación, crítica e interpretación y juicio no solo en el ámbito artístico sino respecto de todas las situaciones que podemos encontrar a lo largo de nuestra vida. (Viadel, 2003, p. 172) 
Es decir, que esta área del conocimiento hace que el individuo, sea un estudiante o educando, un visitante de un museo o un interesado en las artes, tenga nuevas maneras de aproximarse a su pasión para convertir las bases fácticas de las ciencias puras o las apreciaciones esteticistas en parte integral de su realidad.

Empero, es en este punto donde el pensamiento complejo y los principios de Morin (2001) pueden permitir una articulación entre los conocimientos que ya existen sobre cómo ver un trabajo estético, las formas de difundirlos y las visiones que los circundan con el universo del observador, ya que sin importar el contexto donde este habite, son los fundamentos expresados por este autor francés los que logran conectar el mundo interior del sujeto que aprecia la obra con los elementos propios de esta para hacer de su mirada una concepción que vaya desde lo profundo de su interioridad hacia un análisis más extenso de los conocimientos construidos por otros a través de la historia.

\section{Metodología}

El fundamento esencial de este trabajo investigativo será ayudar al investigador a encontrar un enfoque integrador que tenga en cuenta la multiplicidad de saberes que están inmersos en una obra de arte mediante un método cualitativo hermenéutico: «Este enfoque asume el análisis de los aspectos más complejos de la vida humana, de aquello que se encuentra más allá de lo cuantificable» (Fuster, 2019, p. 202).

Partiendo de esta base, el investigador o el profesor deberán tener en cuenta para su proceso de consecución de datos e información un panorama general de los aspectos formales de la obra, tales como: el título de la obra, el autor, el año de creación de la pieza estética, la época, la técnica, la paleta de colores y las dimensiones como un primer acercamiento para contextualizar, en este caso, el grabado de "Melancolía I», apropiadamente a sus educandos.

Por ende, para llegar a una concepción que ayude no solo a apreciar los componentes básicos de la obra, sino también su influencia en diferentes entornos sociales, culturales y educativos, sería válido hacer una aproximación a las concepciones del proceso de comprensión y asimilación de una obra de arte, planteados por Michael. J. Parsons (citado por Esquinas y Sánchez, 2011), que se definen como: «el empírico (mundo exterior), el moral (mundo social), y el estético (mundo interior)» (p. 48), que son el engranaje para analizar cómo el arte es una reunión de elementos holísticos que requieren una interrelación entre creador, espectador y entidades que lo difunden y presentan ante el mundo, para reforzar todo un entramado comunicativo. 
Por consiguiente, con las nociones ya mencionadas, se comienza a construir una lectura interpretativa que se fundamentará en integrar aspectos más profundos de la obra de arte, donde tanto la parte estética como la parte científica, académica y humana serán analizadas no como elementos separados, sino como intersecciones participativas y tanto sus conjunciones como sus disyuntivas serán piezas clave para apoyar el proceso de análisis de una obra de arte.

Sin embargo, para lograr que esta información adquirida del análisis interpretativo de la obra logre vincularse de manera asertiva con las interioridades del sujeto y alcance a llegar a consolidarse dentro de un proceso integrativo, serán los siete principios propuestos por Edgar Morin (2001), planteados en su texto Introducción al pensamiento complejo, que le darán al análisis de la obra "Melancolía I», de Alberto Durero la fuerza suficiente para poder acercarse al universo de los observadores y enriquecer esa visión investigada por el profesor que quiera llevar al aula una nueva manera de entrelazar diferentes clases de elementos al análisis de una pieza estética.

Esta teoría es fundamental para soportar el análisis de la obra ya que demuestra lo importante de analizar una obra de arte desde otras perspectivas más correlacionadas e integradoras y en donde se pasa de la contemplación pasiva o el análisis académico para llegar a una aproximación a la integridad del ser humano en toda su extensión, como lo diría Morín (citado por Pereira, 2010) permitiendo ampliar la definición:

No solo la ciencia puede brindar herramientas de análisis para la epistemología de la complejidad y el enfoque educativo que persigue. La cultura de las humanidades cumple un papel muy importante en esta tarea. Para Morín (2007), las humanidades (las artes, la literatura y la filosofía) nos permiten ver las complejas relaciones del ser humano con el otro, con la sociedad y con el mundo. (p. 72)

Por consiguiente, en la tabla 1 se podrá apreciar la integración entre los principios del paradigma de la complejidad de Morin (2001) y su aplicabilidad al análisis y apreciación de una obra estética con el fin de llegar a la elaboración de una guía de interpretación pedagógica que dé cuenta de la aplicación de un análisis cualitativo hermenéutico y que tenga como base una lectura interpretativa de una obra de arte.

A continuación, se detalla una tabla explicativa de cómo se integrarán estos conceptos dentro de este modelo de apreciación de una pieza estética. 
Tabla 1. Soporte teórico desde el enfoque cualitativo hermenéutico adaptado a los principios de pensamiento complejo de Edgar Morin

\begin{tabular}{|c|c|c|}
\hline $\begin{array}{l}\text { Principios } \\
\text { de Edgar } \\
\text { Morin }\end{array}$ & Definición & $\begin{array}{l}\text { Adaptación de una lectura interpretativa para } \\
\text { la apreciación de una obra de arte desde el } \\
\text { pensamiento complejo }\end{array}$ \\
\hline 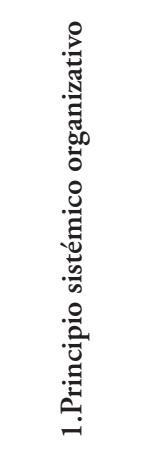 & $\begin{array}{l}\text { Morin (2002, citado } \\
\text { por Leyva, 2009) afir- } \\
\text { ma que, «une el cono- } \\
\text { cimiento de las partes } \\
\text { con el conocimiento del } \\
\text { todo. Opuesta a la idea } \\
\text { (reduccionista), la idea } \\
\text { sistémica afirma que el } \\
\text { todo es más que la suma } \\
\text { de las partes». (p. 5). }\end{array}$ & $\begin{array}{l}\text { En este principio, lo fundamental será invitar al } \\
\text { observador a lograr una aproximación de una pie- } \\
\text { za artística en la cual estén detallados los datos más } \\
\text { importantes de la obra como el autor, el año de } \\
\text { creación, el título de la obra y sus dimensiones, así } \\
\text { como un texto complementario donde se haga refe- } \\
\text { rencia a la integración de las informaciones más rele- } \\
\text { vantes, para hacer de las partes de la obra un todo } \\
\text { integral mediante el análisis de los elementos icono- } \\
\text { gráficos e iconológicos, construyendo un panorama } \\
\text { general donde se le proponga al sujeto una primera } \\
\text { inmersión en la misma. }\end{array}$ \\
\hline 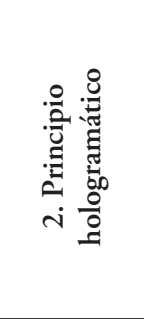 & $\begin{array}{l}\text { Morin (2002, citado } \\
\text { por Leyva, 2009) afirma } \\
\text { que, «del mismo modo } \\
\text { que las partes está en el } \\
\text { todo, el todo está en las } \\
\text { partes». (p. 5). }\end{array}$ & $\begin{array}{l}\text { Este principio se aplicará en el análisis mediante el } \\
\text { contraste de los elementos aislados de la obra con } \\
\text { sus significaciones más profundas desde una lectura } \\
\text { connotativa, donde el observador tendrá las herra- } \\
\text { mientas para no solo comprender los elementos de } \\
\text { la obra, sino también para dar su concepto sobre lo } \\
\text { aprendido y ofrecer su propia interpretación de los } \\
\text { elementos que está apreciando. }\end{array}$ \\
\hline 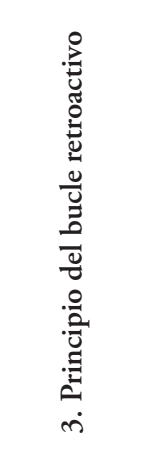 & $\begin{array}{l}\text { Morin (2002, citado } \\
\text { por Leyva, 2009) afir- } \\
\text { ma que, «rompe con el } \\
\text { principio de causalidad } \\
\text { lineal pues, sostiene que } \\
\text { del mismo modo que la } \\
\text { causa actúa sobre el efec- } \\
\text { to, el efecto actúa sobre } \\
\text { la causa». (p. 5). }\end{array}$ & $\begin{array}{l}\text { La aplicación de este principio consistirá en motivar } \\
\text { al observador a realizar una retroalimentación de la } \\
\text { obra, y a su vez, que se gesten nuevas interpreta- } \\
\text { ciones de la misma mediante un proceso donde los } \\
\text { observadores no solo expresen nuevos sentires frente } \\
\text { al grabado que se va a analizar, sino también cons- } \\
\text { truyan nuevas significaciones que les permitan acer- } \\
\text { carse desde su interioridad al imaginario concebido } \\
\text { por el autor, generando una apreciación participati- } \\
\text { va donde el artista, su obra y el observador rompen } \\
\text { los puentes del tiempo y el espacio para reinventar } \\
\text { una nueva manera de entender una pieza estética. }\end{array}$ \\
\hline
\end{tabular}




\begin{tabular}{|c|c|c|}
\hline $\begin{array}{l}\text { Principios } \\
\text { de Edgar } \\
\text { Morin }\end{array}$ & Definición & $\begin{array}{c}\text { Adaptación de una lectura interpretativa para } \\
\text { la apreciación de una obra de arte desde el } \\
\text { pensamiento complejo }\end{array}$ \\
\hline 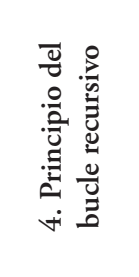 & $\begin{array}{l}\text { Morin (2002, citado por } \\
\text { Leyva, 2009) afirma que, } \\
\text { «los productos y efectos } \\
\text { son a la vez causantes y } \\
\text { productores de lo que } \\
\text { los produce». (p. } 5 \text { ). }\end{array}$ & $\begin{array}{l}\text { Para este principio, la idea de aplicarlo consiste en } \\
\text { involucrar al observador para que este pueda sentir- } \\
\text { se parte de lo que está viendo y pueda expresar ya no } \\
\text { solo una apreciación condicionada, sino que genere } \\
\text { su propia interpretación y utilice lo que aprendió de } \\
\text { la obra estética para redefinirla hacia una experien- } \\
\text { cia más personal. }\end{array}$ \\
\hline 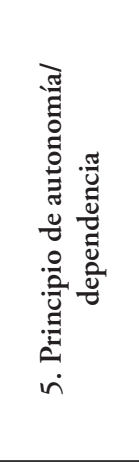 & $\begin{array}{l}\text { Morin (2002, citado } \\
\text { por Leyva, 2009) afirma } \\
\text { que, «los seres humanos } \\
\text { desarrollan su auto- } \\
\text { nomía a partir de los } \\
\text { incesantes intercambios } \\
\text { con la sociedad, cultu- } \\
\text { ra, entorno ecológico, } \\
\text { etc.».(p. 5). }\end{array}$ & $\begin{array}{l}\text { En lo referente a este principio, será el observador } \\
\text { quien se ubique mediante una serie de informa- } \\
\text { ciones previamente suministradas para establecer } \\
\text { un diálogo entre la obra, su artista y su tiempo, } \\
\text { recordando la importancia del contexto histórico y } \\
\text { cultural de la misma, así como la manera en que } \\
\text { esas situaciones pueden identificarse con su pre- } \\
\text { sente, haciendo una asociación entre los entornos } \\
\text { socioculturales que le dieron vida a esa obra y a su } \\
\text { autor y la manera en que estos elementos permean } \\
\text { la modernidad vivida por la persona quien analiza } \\
\text { una pieza estética.. }\end{array}$ \\
\hline 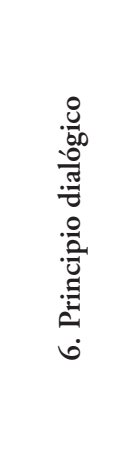 & $\begin{array}{l}\text { Morín (2002, citado } \\
\text { por Leyva, 2009) afir- } \\
\text { ma que, «la asociación } \\
\text { compleja (complemen- } \\
\text { taria/ concurrente/anta- } \\
\text { gonista) de instancias } \\
\text { necesarias, conjunta- } \\
\text { mente necesarias para la } \\
\text { existencia, el funciona- } \\
\text { miento y el desarrollo de } \\
\text { un fenómeno organiza- } \\
\text { do». (p. 6). }\end{array}$ & $\begin{array}{l}\text { La aplicación de este principio consistirá en que el } \\
\text { observador involucre en su análisis no solo los com- } \\
\text { ponentes estéticos, culturales, humanos y estéticos } \\
\text { de la pieza, sino que pueda dialogar participativa- } \\
\text { mente de las apreciaciones que hasta ahora ha ido } \\
\text { adquiriendo y de aportes desde su experiencia para } \\
\text { generar un punto de vista más argumentado sobre } \\
\text { la obra a analizar. }\end{array}$ \\
\hline 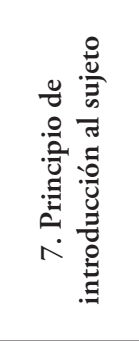 & $\begin{array}{l}\text { Morin (2002, citado } \\
\text { por Leyva, 2009) afirma } \\
\text { que «este último es } \\
\text { una reconstrucción/ } \\
\text { traducción que hace } \\
\text { la mente/cerebro en } \\
\text { una cultura y tiempo } \\
\text { determinados». (p. 6). }\end{array}$ & $\begin{array}{l}\text { Para la aplicación de este principio, el observador } \\
\text { de la obra entra en un dialogo directo con el artista, } \\
\text { entendiendo su trabajo estético, las motivaciones } \\
\text { que lo llevaron al mismo y se busca que produzca } \\
\text { una interacción entre ambos, donde el observador se } \\
\text { ponga en el lugar del artista para establecer un punto } \\
\text { de vista propio, pero con un mayor conocimiento de } \\
\text { las experiencias y situaciones vividas por el creador } \\
\text { de la pieza estética. }\end{array}$ \\
\hline
\end{tabular}

Fuente: Elaboración propia a partir de definiciones tomadas de Morin (citado por Leyva, 2009). 
En síntesis, los anteriores principios se pueden considerar como herramientas de apreciación para diversas obras de arte, en tanto la gran mayoría de propuestas artísticas provienen de una interrelación entre elementos que requieren de una mirada más holística e integradora donde creador, pieza y espectador confluyan en miradas y contextos diversos que resignifiquen una experiencia estética.

Por consiguiente, la tabla 2 sintetizará el enfoque hermenéutico desde las concepciones de Edgar Morin, previamente nombradas.

Tabla 2. Síntesis del enfoque cualitativo hermenéutico adaptado a los principios de pensamiento complejo de Edgar Morin

\begin{tabular}{ll}
\hline \multicolumn{1}{c}{ Principios de Edgar Morín } & \multicolumn{1}{c}{$\begin{array}{c}\text { Bases para la formulación de una interpretación de } \\
\text { una obra artística }\end{array}$} \\
\hline $\begin{array}{l}\text { 1. Principio sistémico } \\
\text { organizativo }\end{array}$ & $\begin{array}{l}\text { "Correlación entre elementos técnicos, compositivos } \\
\text { y simbólicos» (Jiménez, 2016, p. 68). }\end{array}$ \\
\hline 2. Principio hologramático & $\begin{array}{l}\text { «Diálogo transdisciplinar con el objeto artístico des- } \\
\text { de una visión holística» (Jiménez, 2016, p. 71). }\end{array}$ \\
\hline 3. Principio del bucle retroactivo & $\begin{array}{l}\text { «Retrospectiva espaciotemporal de la obra» (Jiménez, } \\
\text { 2016, p. 71). }\end{array}$ \\
\hline 4. Principio del bucle recursivo & $\begin{array}{l}\text { Resignificación de la obra a través del razonamiento } \\
\text { y la intuición de sus realidades. }\end{array}$ \\
\hline $\begin{array}{l}\text { 5. Principio de autonomía } \\
\text { dependencia }\end{array}$ & $\begin{array}{l}\text { Interconexión histórica y cultural a través de tiempos } \\
\text { comunes o distintos entre la obra y su observador. }\end{array}$ \\
\hline 6. Principio dialógico & $\begin{array}{l}\text { El observador como constructor de una aprecia- } \\
\text { ción contrastante que lo lleva al entendimiento de } \\
\text { una obra. }\end{array}$ \\
\hline 7. Principio de introducción al & $\begin{array}{l}\text { Co-relación artista-sujeto desde su multidimensiona- } \\
\text { lidad, su creación, percepción y pensamiento. }\end{array}$ \\
sujeto &
\end{tabular}

Bajo esta metodología, los espectadores pueden generar una labor interactiva e interconectada donde el estudio de una obra de arte entrelace los conocimientos epistemológicos con un amplio sentido de humanidad e interconectividad que es posible usar para interpretaciones futuras en diferentes contextos, y cuya mayor preponderancia estará en la enseñanza de la apreciación del arte como una manera de provocar que el educando se relacione más directamente con obras de épocas distantes o cercanas en el tiempo y no como elementos aislados, a fin de formar construcciones teóricas que toquen de manera intrínseca su propia realidad. 


\subsection{Muestra}

Este instrumento se aplicó a cinco profesionales que oscilaban entre los 36 a los 60 ańos de diferentes áreas del saber científico, cultural, educativo y pedagógico, quienes fueron elegidos intencionalmente por su formación académica plural y su interés en profundizar sus conocimientos sobre el mundo del arte, con el objetivo de estimular a los participantes a construir sus aportaciones particulares sobre la obra "Melancolía I» de Alberto Durero para que puedan aplicarse a diferentes procesos referentes a la educación de la mirada artística y la estética en escenarios formativos.

\subsection{Instrumento y procedimiento de aplicación}

Se elaboró una guía de interpretación pedagógica validada por expertos en forma de cuestionario divida en tres partes. La primera se denominó ficha del observador y buscaba recoger los datos de los cinco profesionales seleccionados en la muestra quienes escribieron su nombre completo, edad y nivel educativo alcanzado.

Para la segunda parte se desarrolló una pequeña guía introductoria en la que se especificó el nombre de la pieza artística, el artista, su año de elaboración, su contexto histórico, la técnica artística usada, el manejo del color y sus proporciones, acompañada de una ilustración impresa del grabado. Posteriormente, se realizó una corta referenciación histórica para que los participantes pudieran lograr una percepción más clara sobre la obra y generar una reflexión más elaborada de esta pieza estética.

Por último, se realizaron nueve (9) preguntas tipo cuestionario. Estas iban desde el análisis del concepto de melancolía en el contexto social de la época y la interpretación que le dio el autor, pasando por interrogantes analizaron elementos principales y detallados de esta pieza estética con el objetivo de interrelacionar los componentes más particulares de la obra con las vivencias personales de los observadores elegidos para la aplicación del instrumento previamente mencionado.

Estas preguntas se diseńaron teniendo en cuenta los siete principios de Morin (2001) planteados en su texto Introducción al pensamiento complejo que para cuestiones de análisis dentro de esta investigación, se analizan en un orden aleatorio, el cual no está relacionado con la manera en que se presentó en la guía, ya que se buscaba hacer un proceso de internalización lógico y de fácil manejo para los sujetos seleccionados en la aplicación del material: 
Tabla 3. Análisis para la elaboración de la guía de interpretación pedagógica

\begin{tabular}{|c|c|c|c|}
\hline $\begin{array}{l}\text { Principio } \\
\text { de Edgar } \\
\text { Morin }\end{array}$ & $\begin{array}{c}\text { Aplicación en la } \\
\text { comprensión estética } \\
\text { de una pieza artística }\end{array}$ & $\begin{array}{c}\text { Relación del principio } \\
\text { con la construcción de } \\
\text { la guía de interpretación } \\
\text { pedagógica }\end{array}$ & $\begin{array}{c}\text { Pregunta del cuestionario } \\
\text { en relación con los } \\
\text { principios de Morin } \\
\text { para el análisis de la } \\
\text { obra «Melancolía I» de } \\
\text { Alberto Durero }\end{array}$ \\
\hline
\end{tabular}

1. Principio sistémico organizativo
Correlación entre elementos técnicos compositivos y simbólicos.
«Aumenta el sentido de comprensión del observador por medio de los elementos iconográficos e iconológicos de la obra que son puestos a consideración para ayudarle a desarrollar su primer acercamiento" (Jiménez, 2016, p. 107).

\begin{abstract}
Pregunta 7
«¿Cómo percibe la obra frente a diversos aspectos tales como: la representación del tiempo; el encuadre visual; la distribución del espacio; el sentido de las líneas; la representación de las formas?» (Jiménez, 2016, p. 100).
\end{abstract}

Pregunta 3

«La obra percibida compone distintos elementos o formas autónomamente, clasifíquelas en una lista detalladamente de acuerdo con tres categorías que usted considere y titule cada una y explique las razones de esta selección» (Jiménez, 2016, p. 99).

\section{Principio} hologramático
Diálogo entre la obra de arte y el observador desde una perspectiva holística.

\begin{abstract}
«Donde la obra denota una serie de elementos aislados que permiten acercarse a la intención del autorh desde la cual es posible contrastarlos con sus particularidades, generando una visión holística entre el conocimiento de cada sujeto contemplador y la idea expresada por el creador» (Jiménez, 2016, p. 107).
\end{abstract}

Pregunta 4

«A partir de las siguientes preguntas, reflexione sobre el primer personaje del grabado (El ángel) y de acuerdo a las categorías que usted propuso y los elementos contenidos en ellas plantee una relación entre este personaje y su disciplina: ¿qué es lo que cree que este personaje es capaz de hacer con estos elementos?; ¿qué es lo que cree que este personaje quiere hacer con estos elementos?; ¿qué es lo que cree que debería hacer con estos elementos?» (Jiménez, 2016, p. 99). 


$\begin{array}{cc}\text { Principio } & \begin{array}{c}\text { Aplicación en la } \\ \text { de Edgar } \\ \text { Morin }\end{array} \\ \text { comprensión estética } \\ \text { de una pieza artística }\end{array}$

Relación del principio con la construcción de la guía de interpretación pedagógica
Pregunta del cuestionario en relación con los principios de Morin para el análisis de la obra «Melancolía I» de Alberto Durero

$\begin{array}{ll}\text { 3. Principio } & \text { Interrelación contex- } \\ \text { del bucle } & \text { tual entre el lugar y } \\ \text { retroactivo } & \text { el tiempo de la obra } \\ & \text { "Melancolía I». }\end{array}$

3. Principio del bucle

\begin{abstract}
«Genera una retroalimentación donde el observador aprenda de la obra y la obra en sí se alimente de las concepciones del observador, para construir una reflexión que allané el camino a nuevos observadores que posteriormente puedan ofrecer sus propias interpretaciones» (Jiménez, 2016, p. 107).
\end{abstract}

«Genera en el observador una interpretación de consciencia estética donde involucre sus sentimientos, experiencias, puntos de vista y teorías que generen una reflexión profunda, sin descartar los matices propios de este grabado $\mathrm{y}$ las teorías existentes sobre su comprensión y análisis» (Jiménez, 2016, p. 108).

\section{Pregunta 2}

"¿Cuál fue la primera percepción que la obra "Melancolía I" produjo en usted?» (Jiménez, 2016, p. 99).
Pregunta 8
"¿Cómo relaciona la obra con
su propia realidad?» (Jimé-
nez, 2016, p. 100).
Pregunta 6
"¿Cómo aplicaría la obra
de "Melancolía I" para
explicar un concepto de su
área disciplinar?» (Jiménez,
2016, p. 100).

Pregunta 1

"¿Por qué cree usted que el artista Alberto Durero le dio el nombre de "Melancolía I" a esta obra?" (Jiménez, 2016, p. 99).
«A través del concepto de melancolía, explicado dentro de la reseña de la obra, se busca que el observador de manera independiente asocie el dilema que el artista expresa en su obra entre el genio creador y el artesano, generando una opinión autónoma pero dependiente de la información que este recibe del concepto de melancolía. Artista Creador-Visión de la realidad" (Jiménez, 2016, p. 108). 


\begin{tabular}{|c|c|c|c|}
\hline $\begin{array}{l}\text { Principio } \\
\text { de Edgar } \\
\text { Morin }\end{array}$ & $\begin{array}{l}\text { Aplicación en la } \\
\text { comprensión estética } \\
\text { de una pieza artística }\end{array}$ & $\begin{array}{l}\text { Relación del principio } \\
\text { con la construcción de } \\
\text { la guía de interpretación } \\
\text { pedagógica }\end{array}$ & $\begin{array}{l}\text { Pregunta del cuestionario } \\
\text { en relación con los } \\
\text { principios de Morin } \\
\text { para el análisis de la } \\
\text { obra «Melancolía I» de } \\
\text { Alberto Durero }\end{array}$ \\
\hline $\begin{array}{l}\text { 6. Principio } \\
\text { dialógico }\end{array}$ & $\begin{array}{l}\text { El individuo observa- } \\
\text { dor que pasa a ser un } \\
\text { autor-lector de una } \\
\text { obra de arte. }\end{array}$ & $\begin{array}{l}\text { "Trata de establecer una } \\
\text { conexión entre la obra, su } \\
\text { iconografía e iconología } \\
\text { y su pensamiento propio, } \\
\text { que le permita no solo } \\
\text { diferenciar categorías sino } \\
\text { contrastarlas con su imagi- } \\
\text { nario personal» (Jiménez, } \\
\text { 2016, p. 108). }\end{array}$ & $\begin{array}{l}\text { Pregunta } 5 \\
\text { "¿Qué criterios establecería } \\
\text { para desarrollar una relación } \\
\text { entre las categorías seleccio- } \\
\text { nadas dentro de la aprecia- } \\
\text { ción que usted está realizan- } \\
\text { do de la obra "Melancolía } \\
\text { I"? Menciónelos y justifíque- } \\
\text { los claramente» (Jiménez, } \\
2016 \text {, p. 99). } \\
\text { Pregunta } 3 \\
\text { "La obra percibida compone } \\
\text { distintos elementos o formas } \\
\text { autónomamente. Clasifíque- } \\
\text { las en una lista detalladamen- } \\
\text { te de acuerdo con tres cate- } \\
\text { gorías que usted considere, } \\
\text { titule cada una y explique } \\
\text { las razones de esta selección» } \\
\text { (Jiménez, 2016, p. 99). }\end{array}$ \\
\hline $\begin{array}{l}\text { 7. Principio } \\
\text { de } \\
\text { introducción } \\
\text { al sujeto }\end{array}$ & $\begin{array}{l}\text { «Paralelismo entre la } \\
\text { obra "Melancolía I" y } \\
\text { su autor como artis- } \\
\text { ta-sujeto» (Jiménez, } \\
\text { 2016, p. 91). }\end{array}$ & $\begin{array}{l}\text { «El artista inconsciente- } \\
\text { mente hace una concreción } \\
\text { de una realidad externa e } \\
\text { interna que refleja su esen- } \\
\text { cia particular a través de un } \\
\text { lenguaje propio de un crea- } \\
\text { dor y la mente del observa- } \\
\text { dor, que hace una interpre- } \\
\text { tación particular sin olvidar } \\
\text { su entorno de vida» (Jimé- } \\
\text { nez, 2016, p. 109). }\end{array}$ & $\begin{array}{l}\text { Pregunta } 9 \\
\text { "Teniendo en cuenta que este } \\
\text { cuadro fue creado en el Rena- } \\
\text { cimiento, ¿cómo cree usted } \\
\text { que fue la vida de Durero y } \\
\text { cómo está plasmada su vida } \\
\text { dentro de la obra?» (Jiménez, } \\
2016 \text {, p. 100). }\end{array}$ \\
\hline
\end{tabular}

Fuente: Elaboración propia a partir de Pensamiento complejo y apreciación estética en la obra "Melancolía I" de Alberto Durero (Jiménez, 2016). 


\section{Resultados}

Una vez realizada la aplicación de la guía metodológica, los observadores lograron llegar a una serie de conclusiones que serán sintetizadas en la tabla 4, la cual referencia, en primer lugar, la manera como fueron permeados por la vida del autor, la manera en que hicieron paralelos entre la obra y sus diferentes áreas del saber, los elementos asociativos que encontraron en sus vidas, sus sentimientos y cómo el grabado "Melancolía I» de Alberto Durero podría verse reflejado en estos, así como la manera en que se podría realizar un diálogo entre la época en la que se realizó el grabado con la actualidad.

Tabla 4. Resultados a partir de la guía de interpretación pedagógica

Perfiles de los observadores:

Observador 1: Artista plástico - 60 años

Observador 2: Ingeniero de sistemas - 40 ańos

Observador 3: Estudiante de lenguas modernas - 32 años

Observador 4: Contador - 37 años

Observador 5: Profesor de español e inglés - 40 años

Diferencias

Pregunta 3

«La obra percibida compone distintos elementos o formas autónomamente, clasifíquelas en una lista detalladamente de acuerdo con tres categorías que usted considere y titule cada una, y explique las razones de esta selección» (Jiménez, 2016, p. 99).

Pregunta 7

«Cómo percibe la obra frente a diversos aspectos tales como: la representación del tiempo; el encuadre visual; la distribución del espacio; el sentido de las líneas; la representación de las formas?» (Jiménez, 2016, p. 100).
Los observadores 1 y

2 generaron categorías comunes que expresan lo que perciben de obra basados en los sentimientos y emociones.

\section{Mientras tanto, los obser- vadores 3 y 4 se enfocaron más en los elementos de la naturaleza, y el observador 5 en elementos humanos cien- tíficos y espirituales.}

Para los observadores Para el observador 3, se aso1, 2, 4 y 5, la obra está cia más la parte técnica con totalmente asociada a la parte emocional. aspectos compositivos del pasado y técnicas que evocan la precisión y el buen manejo de la forma. 


\begin{tabular}{|c|c|c|c|}
\hline 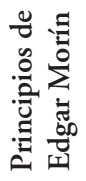 & Preguntas & Aspectos en común & Diferencias \\
\hline 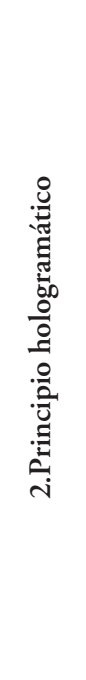 & $\begin{array}{l}\text { Pregunta } 4 \\
\text { «A partir de las siguientes } \\
\text { preguntas reflexione sobre el } \\
\text { primer personaje del grabado } \\
\text { (El ángel), y de acuerdo a las } \\
\text { categorías que usted propuso } \\
\text { y los elementos contenidos } \\
\text { en ellas plantee una relación } \\
\text { entre este personaje y su dis- } \\
\text { ciplina: ¿qué es lo que cree } \\
\text { que este personaje es capaz } \\
\text { de hacer con estos elemen- } \\
\text { tos?; ¿qué es lo que cree que } \\
\text { este personaje quiere hacer } \\
\text { con estos elementos?; ¿qué es } \\
\text { lo que cree que debería hacer } \\
\text { con estos elementos?» (Jimé- } \\
\text { nez, 2016, p. 99). }\end{array}$ & $\begin{array}{l}\text { Para los observadores } 2 \\
\text { y } 3 \text {, los elementos de la } \\
\text { obra se reflejaron en sus } \\
\text { propios sentimientos, } \\
\text { emociones y formas de } \\
\text { sentir frente a la manera } \\
\text { de desarrollar sus profe- } \\
\text { siones en contraste con } \\
\text { el personaje de la obra. }\end{array}$ & $\begin{array}{l}\text { Los observadores } 1 \text { y } 5 \text { res- } \\
\text { pondieron a esta pregunta } \\
\text { mediante la sustentación } \\
\text { de las ideas propuestas en } \\
\text { la pregunta } 3 \text {, pero desde } \\
\text { perspectivas académicas } \\
\text { relevantes a sus profesiones. } \\
\text { En cuanto al observador } 4 \text {, } \\
\text { aunque también sustentó } \\
\text { sus respuestas a la pregun- } \\
\text { ta } 3 \text {, no lo hizo desde su } \\
\text { área de conocimiento sino } \\
\text { desde el planteamiento de } \\
\text { verbos cortos en formato de } \\
\text { objetivos. }\end{array}$ \\
\hline 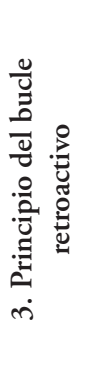 & $\begin{array}{l}\text { Pregunta } 2 \\
\text { "¿Cuál fue la primera per- } \\
\text { cepción que la obra "Melan- } \\
\text { colía I" produjo en usted?" } \\
\text { (Jiménez, 2016, p. 99). }\end{array}$ & $\begin{array}{l}\text { Para los observadores } 2, \\
3,4 \text { y } 5 \text { el objeto prin- } \\
\text { cipal de su observación } \\
\text { y lo que más los conectó } \\
\text { con la obra en un primer } \\
\text { acercamiento fue la sen- } \\
\text { sación que les inspiraban } \\
\text { los personajes centrales } \\
\text { de la obra y los gestos } \\
\text { que ellos reflejaban. }\end{array}$ & $\begin{array}{l}\text { Por su parte, el primer } \\
\text { observador se distanció de } \\
\text { los personajes de la obra } \\
\text { e hizo un puente entre su } \\
\text { labor como artista plástico } \\
\text { y el trabajo del creador, con- } \\
\text { siderando que los personajes } \\
\text { eran una representación de } \\
\text { los sentimientos de este. }\end{array}$ \\
\hline
\end{tabular}




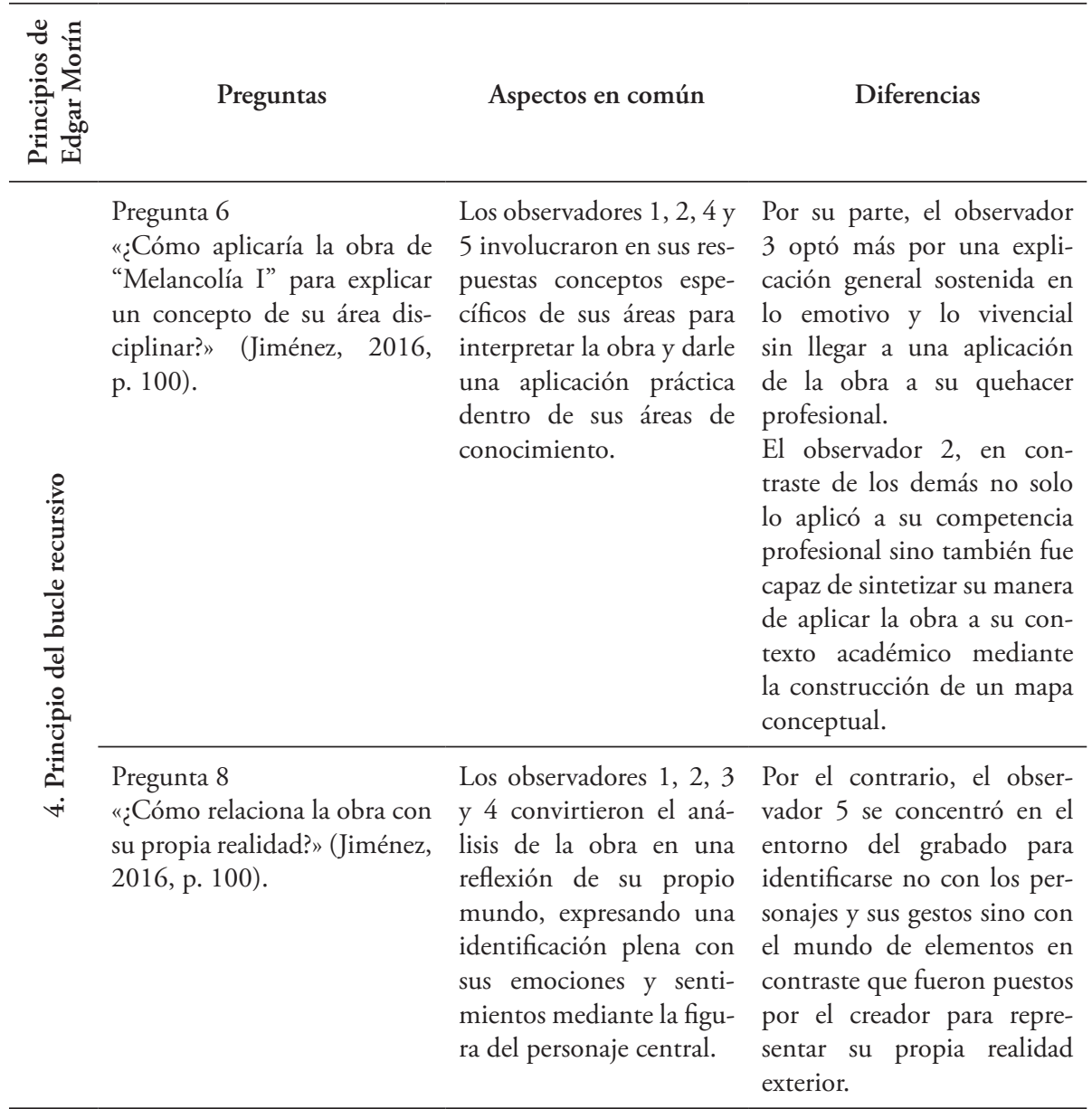

$\begin{array}{ll} & \begin{array}{l}\text { Pregunta } 1 \\ \text { "Por qué cree usted que el }\end{array} \\ \text { artista Alberto Durero le dio } \\ \text { el nombre de "Melancolía }\end{array}$

Para los observadores 2, 3, y 4, son las sensaciones interiores expresadas por su primer acercamiento con la obra "Melancolía I" lo que hace el puente entre su primera exploración de la pieza estética y su propio entorno emocional.

Por su parte, el observador
1 ya tenía un conocimiento
de las obras del mismo autor
y pudo establecer una cone-
xión más epistemológica.
Asimismo, el observador 5
hizo una correlación con sus
conocimientos de la historia
del arte y en su primera apro-
ximación le dio más énfasis
al trasfondo humanístico
que a lo vivencial-personal.




\begin{tabular}{|c|c|c|c|}
\hline 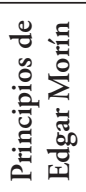 & Preguntas & Aspectos en común & Diferencias \\
\hline \multirow{2}{*}{ 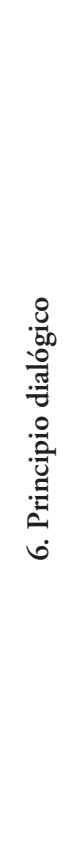 } & $\begin{array}{l}\text { Pregunta } 3 \\
\text { «La obra percibida compone } \\
\text { distintos elementos o formas } \\
\text { autónomamente. Clasifíque- } \\
\text { las en una lista detalladamen- } \\
\text { te de acuerdo a tres categorías } \\
\text { que usted considere, titule } \\
\text { cada una y explique las razo- } \\
\text { nes de esta selección» (Jimé- } \\
\text { nez, 2016, p. 99). }\end{array}$ & $\begin{array}{l}\text { Los observadores 1, } 3, \\
4, \text { y } 5 \text { lograron descom- } \\
\text { poner los elementos de } \\
\text { la obra en aspectos con- } \\
\text { cretos como la ciencia, la } \\
\text { historia o la matemática, } \\
\text { eligiendo la concreción } \\
\text { de los elementos presen- } \\
\text { tes en el grabado. }\end{array}$ & $\begin{array}{l}\text { Por el contrario, el observa- } \\
\text { dor } 2 \text { destacó más los fac- } \\
\text { tores emocionales dentro de } \\
\text { los elementos compositivos } \\
\text { de la obra, predominando } \\
\text { su percepción emotiva sobre } \\
\text { sus conocimientos en alguna } \\
\text { área de la ciencia puntual. }\end{array}$ \\
\hline & $\begin{array}{l}\text { Pregunta } 5 \\
\text { "¿Qué criterios establecería } \\
\text { para desarrollar una relación } \\
\text { entre las categorías seleccio- } \\
\text { nadas dentro de la aprecia- } \\
\text { ción que usted está realizando } \\
\text { de la obra "Melancolía I”? } \\
\text { Menciónelos y justifíque- } \\
\text { los claramente» (Jiménez, } \\
\text { 2016, p. 99). }\end{array}$ & $\begin{array}{l}\text { Complementando a la } \\
\text { propuesta de categori- } \\
\text { zación de la pregunta } 3 \text {, } \\
\text { solo los observadores } 1 \\
\text { y } 5 \text { justificaron de una } \\
\text { manera más profunda la } \\
\text { división de las categorías } \\
\text { escogidas a planos de las } \\
\text { ciencias humanas. }\end{array}$ & $\begin{array}{l}\text { En contraposición, los } \\
\text { observadores } 3 \text { y } 4 \text { no logra- } \\
\text { ron justificar la mención de } \\
\text { los componentes científicos } \\
\text { mencionados en las catego- } \\
\text { rías y optaron seguir su sen- } \\
\text { tir emocional. } \\
\text { Por su parte, el observador } \\
2 \text { amplió mediante un mapa } \\
\text { conceptual su justificación } \\
\text { emotiva de los elementos } \\
\text { de la obra. }\end{array}$ \\
\hline 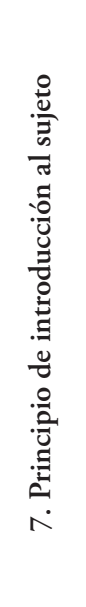 & $\begin{array}{l}\text { Pregunta } 9 \\
\text { «Teniendo en cuenta que este } \\
\text { cuadro fue creado en el Rena- } \\
\text { cimiento, ¿cómo cree usted } \\
\text { que fue la vida de Durero y } \\
\text { cómo está plasmada su vida } \\
\text { dentro de la obra?» (Jiménez, } \\
2016 \text {, p. 100). }\end{array}$ & $\begin{array}{l}\text { Los observadores } 1 \text { y } 5 \text {, par- } \\
\text { tiendo de su conocimiento } \\
\text { particular sobre la época de } \\
\text { la obra y su autor, ofrecen } \\
\text { una mirada histórica para } \\
\text { hacer una reconstrucción } \\
\text { desde su saber sobre lo que } \\
\text { el autor y la obra represen- } \\
\text { taban en el arte. } \\
\text { Por su parte los observado- } \\
\text { res } 3 \text { y } 4 \text { utilizaron la obra } \\
\text { para hacerse una imagen } \\
\text { del trasfondo emocional } \\
\text { que pudo haber sentido } \\
\text { el autor al momento de } \\
\text { construir la pieza estética. }\end{array}$ & $\begin{array}{l}\text { Por su parte, el observador } 2 \\
\text { ve al autor y a su época como } \\
\text { una reconstrucción de sus } \\
\text { propias percepciones sobre } \\
\text { su presente, concentrándo- } \\
\text { se más en lo que el mismo } \\
\text { observador siente frente a su } \\
\text { momento actual que a lo que } \\
\text { la obra le resignifica. }\end{array}$ \\
\hline
\end{tabular}

Fuente: Elaboración propia a partir de Pensamiento complejo y apreciación estética en la obra "Melancolía I" de Alberto Durero (Jiménez, 2016). 
A partir de estos hallazgos logrados mediante esta guía metodológica, el profesor, tutor o guía de un proceso de formación artística o de introducción al mundo del arte podrá facilitar el acercamiento a todo tipo de observadores, generando "transformaciones amorosas entre el creador, el espectador, la materia y el juego que se establece entre ellos» (Viadel, 2003, p. 167), para que así sea la interconexión entre los componentes presentes en diversos tipos de obras la que vaya más allá de la historicidad o el análisis formal para generar un puente entre las audiencias que relacione lo que ven con su interioridad, haciendo del docente un guía idóneo para acercar a los observadores a las obras no solo desde la materia estética en sí, sino también de la esencia misma del sujeto apreciador.

Por consiguiente, ejemplos como "Melancolía I», analizan no solo los componentes iconográficos e iconológicos de una obra, sino también invita a las personas de diferentes enfoques disciplinarios a realizar una apropiación desde múltiples perspectivas que abarquen su entorno personal, su ámbito académico, sus sentimientos íntimos frente al mundo que lo rodea para conectarse con una experiencia apreciativa de doble vía. «En el ámbito artístico no se trata de desintegrar la complejidad de lo real en un argumento simple y ordenado que ofrezca una solución, sino de enseñar un modo de pensar, o muchos si fuera el caso» (Acosta y Viramontes, 2013, s.f.).

Por lo tanto, esta guía es además una de las nuevas herramientas que puede ayudar a los observadores a emprender el a veces complejo camino de la interpretación y acercamiento a una obra de arte, confrontando sus saberes mediante la interrelación entre los fundamentos de Morin (2001) como una alternativa válida en el proceso de integración de una mirada multidimensional a los posibles significados que puede contener una pieza estética.

\section{Discusión}

En primer lugar, es importante enfatizar que el arte y sus representaciones estéticas no pueden analizarse bajo la perspectiva de una metodología representativa, sino que, para lograr un análisis complejo, detallado y no excluyente, es necesario abarcar diferentes tendencias que permitan articular las significaciones latentes presentes en una obra de arte, así como los contextos sociales, culturales e incluso ideológicos que le dieron cabida y le permitieron permear la barrera de la historia.

Es por ello que esta investigación busca aportar una nueva metodología, teniendo en cuenta los principios de Edgar Morin (2001) como fundamento holístico que permite acercar a distintos públicos a la interpretación de una 
obra de arte. Varios autores a lo largo de la historia han aportado al tema de la apreciación desde diversos enfoques que permiten el análisis y la comprensión de una pieza estética desde valores contextuales, compositivos, semióticos entre otros.

Por consiguiente, a la hora de presentar los diferentes tipos de análisis que dieron cabida a la interpretación actual del concepto de apreciación del arte bajo la noción contextual, es importante referenciar a Hipólito Taine (1828-1893) (citado por Fernández, 2003) quien sostenía que "las producciones del espíritu humano, como las de la naturaleza, solo pueden explicarse por el medio que las produce» (p. 52).

Por otra parte, al contrastar las ideas de Taine (citado por Fernández, 2003) en su texto Hipólito Taine: la obra de arte como hija de su tiempo) con el pensamiento holístico de Morin (2001), es posible relacionarlas mediante la noción del 'bucle recursivo', donde es el objeto causante y a la vez producto de los contextos. Tanto Taine como Morin entendían que una pieza estética por sí misma es generada para responder a las necesidades de un contexto determinado, pero a la vez se nutre del mismo para construir su propia identidad, tal como se menciona en las preguntas 6 y 8 de la guía de interpretación pedagógica (ver Tabla 4) donde el observador le da una nueva interpretación a una obra del pasado desde sus percepciones presentes, renovando la percepción de una pieza estética con sus visiones personales.

En segunda medida, el concepto de composición ha sido otro de los fundamentos teóricos con los que se ha logrado edificar un análisis de la mirada a partir de la obra de arte en sí misma, desarrollado por el académico alemán Rudolf Arnhein (1904-2007) (1980), quien sostiene que la apreciación de una pieza estética depende de la «segregación [...]. Las partes más grandes se subdividen a su vez en partes menores y la tarea del artista consiste en adaptar el grado y la clase de segregaciones y conexiones a la significación que pretende trasmitir» (p. 66).

De esta manera, al mirar una obra de arte desde un punto de vista holístico que permita entender cualquier tipo de trabajo estético, es necesario llegar al principio sistémico de Morin (2001), quien como Arnhein (1980) explica la importancia de las partes como el fundamento de todo el conocimiento y que para llegar al entendimiento de una idea es necesario referenciar cada uno de sus componentes como base de un todo.

Adicionalmente, es necesario destacar la investigación de Erwin Panofsky (1892 -1968), que contribuye a darle al investigador mayores piezas para que pueda ampliar sus perspectivas de análisis cuando sostiene que: 
Funde, y transforma, dos grandes representaciones literarias, la de la Melancolía como uno de los Cuatro Humores y la de la Geometría como una de las Siete artes Liberales. Tipifica al artista del Renacimiento que respeta la pericia práctica, pero anhela con tanto mayor fervor la teoría matemática; que se siente «inspirado» por influjos celestiales e ideas eternas, que sufre tanto más hondamente por su fragilidad humana y su finitud intelectual. (Panofsky, 1955, p. 177)

Los aportes de este autor hacen posible una ampliación de la obra artística desde una connotación semiótica a partir de aspectos iconográficos e iconológicos que subyacen en la obra de arte, enfocándose especialmente en la obra de Alberto Durero, mostrando la importancia no solo de analizar la forma, sino el fondo de todos los elementos que la componen y que, en este documento, contribuirán al observador en su acercamiento y comprensión de la pieza antes mencionada (ver Tabla 4, pregunta 7).

\section{Conclusiones}

Esta investigación surgió con el propósito de edificar una herramienta pedagógica para apoyar los procesos de apreciación de la mirada para la interpretación de una obra estética bajo la perspectiva de los principios del pensamiento complejo, planteados por Edgar Morin (2001). Bajo este enfoque, se eligió «Melancolía I», ya que este grabado ofrece el reto de presentar al observador elementos heterogéneos que cubren distintas disciplinas desde la matemática, la estética e incluso la medicina, entre otras.

De este modo, esta herramienta o guía puede ser usada por el profesor como una alternativa novedosa para apoyar diferentes procesos pedagógicos, como clases de historia del arte e incluso exhibiciones artísticas e históricas en museos por medio de una propuesta epistemológica y holística diferente, en donde, manteniendo los siete fundamentos acuñados por Morín (2001) y la interrelación de la obra con sus observadores, se produzca una reflexión entretejida que conecte épocas, elementos y concepciones.

En cuanto a la reflexión que hicieron los observadores a través de esta guía metodológica, se logró evidenciar una nueva alternativa para construir una interpretación sensible, crítica y reflexiva por medio del arte (en este caso, el grabado), y así develar algunos elementos de toda la multiplicidad contenidos en obras de profunda complejidad como "Melancolía I», que se convierten en la mejor manera de incentivar a las personas a realizar una aproximación intima pero argumentada de la misma, y que asimismo permiten conocer perspectivas que unan los conocimientos estéticos especializados con su forma de apreciar la realidad. 
Por consiguiente, la aplicación de esta guía deja en claro que los sujetos de investigación se compenetraron directamente con el sentir de la obra al convertir los referentes semióticos existentes en la pieza artística en elementos significativos dentro de su propio andamiaje personal y profesional para traducir dentro de su universo muchos de los componentes estéticos del grabado «Melancolía I» (1514) relacionándolos con su entorno cotidiano, venciendo los puentes del tiempo para identificar una obra elaborada en el Renacimiento como parte de sus vivencias actuales y llevarlos a reinterpretar desde su imaginario un trabajo artístico que en un momento podría ser distante para ellos, pero que por medio de este tipo de análisis logra conectar el grabado a su presente.

Por ende, al usar el análisis de una obra de arte a partir de la síntesis planteada en el documento, también puede ser aplicada a diversas piezas de carácter estético buscando involucrar a los observadores en una forma diferente de acercarse a una obra de arte, y brindarle a profesores de diferentes áreas del saber una manera en la que puedan integrar las experiencias o concepciones de sus educandos, no solo a los procesos de comprensión de una pieza estética, sino también para desarrollar una propuesta de énfasis hacia la educación artística donde se motive a diferentes clases de audiencias a construir una aproximación argumentada sobre el contenido de una pieza estética con sus propias aportaciones, aunque teniendo en cuenta estudios previos que amplíen significativamente los conceptos a los que puedan llegar para lograr una apreciación más profunda de cualquier pieza estética que no descarte la interioridad presente en cada observador.

Adicionalmente, otra de las apreciaciones que se han logrado establecer es que, al haber diversas fuentes de aproximación a una pieza estética donde se integran apreciaciones académicas y empíricas, se logra incentivar a diferentes grupos de espectadores a acercarse a un análisis sin el recelo de sentir que sea una experiencia que los sobrepase, sino una posibilidad de asociar a su propia perspectiva formas estéticas que a pesar de provenir de épocas distantes a su contexto, y que de esta manera puedan aprender sobre los componentes, motivaciones e incluso elementos humanos que hacen parte de este trabajo y tener herramientas para brindar apreciaciones propias pero con profundidad y conocimiento de lo que la obra puede ofrecerles a sus propias vidas.

Este proceso fue posible gracias a una aproximación holística provenientes de los principios previamente reseńados, que fueron concebidos por Morin (2001) como parte de su Teoría de comprensión de la realidad, abriendo la puerta a un diálogo intertextual entre obra, autor, observador y entorno para convertir una obra de arte en una conversación interconectada entre todos sus elementos y las personas que deseen avanzar en el proceso de construir aportes más entrelazados de lo que representan las características de una pieza estética. 
En conclusión, es válido tener presente que este artículo es solo el primer paso en el camino para ayudar al profesor y al observador de una obra de arte a tener nuevas herramientas pedagógicas y cognoscitivas para dialogar junto con sus educandos sobre las alternativas para aproximarse aún más a pieza de carácter estético y así generar, mediante la complejidad, una alternativa para abarcar los estudios existentes sobre una pieza artística sin perder lo que sus estudiantes o audiencias en general puedan aportar mediante la adquisición necesaria de las herramientas que los guíen a lo largo de su viaje exploratorio a través de puntos de vista epistemológicamente recientes, como lo son las ciencias de la complejidad.

\section{REFERENCIAS BIBLIOGRÁFICAS}

Acosta, J. y Viramontes, S. (2013). Arte y pensamiento complejo. Universidad Autónoma de Zacatecas. Recuperado de http://www.seeci.net/

Agrippa, C. (2005). Filosofía oculta. Buenos Aires: Kier.

Arnhein. R. (1980). Arte y percepción visual, Psicología del ojo creador. Alianza Editorial. Recuperado de https://monoskop.org/images/9/9e/Arnheim_ Rudolf_Arte_y_percepcion_visual.pdf

Barbosa, A. (2018). Construcción dialógica ciencia/arte. Estética del alea desde el enfoque de la complejidad. Panambí, (6), 135-152. https://doi. org/10.22370/panambi.0.6.1138

Bielewicz, J., Górniak., A. y Rejdak, K. (2017). Los conflictos religiosos y su posible relación con los trastornos psicosomáticos en el siglo XVII: Anatomía de la melancolía de Robert Burton. Neurosciences and History, 5(3), 88-93. Recuperado de https://nah.sen.es/vmfiles/abstract/ NAHV5N3201788_93ES.pdf

Constantinescu, D. (2011). El infinito simbólico de la metáfora poética, Alberto Durero, Melancolía I. Revista Disertaciones, (2), 2-32. Recuperado de http://academia.uniquindio.edu.co/academia/revistas/disertaciones/doc2/ articulo_Traduccion_Doina_Constantinescu.pdf

Durero, A. (1514). Melancolía I [Hueco grabado]. Galería Nacional de Arte de Karlsruhe, Karlsruhe, Alemania. Recuperado de https://www.kunsthallekarlsruhe.de/kunstwerke/Albrecht-D\%c3\%bcrer/Melencolia-I-Die-Mela ncholie/6ABE53364495E90C2D7B0E8D99C2B03B/\#

Esquinas, F. y Sánchez, M. (2011). Dibujo: artes plásticas y visuales, complementos de formación disciplinar. Espańa: Ministerio de Educación Cultura y Deporte, Secretaría General Técnica: Graó. Recuperado de https://dialnet. unirioja.es/servlet/libro?codigo $=452695$ 
Fernández, C. (2003). Hipólito Taine: la obra de arte como hija de su tiempo. Artes la revista, 3(6), 49-63. Recuperado de https://dialnet.unirioja.es/ servlet/articulo?codigo $=1213952$

Fuster, D. (2019). Investigación cualitativa: Método fenomenológico hermenéutico. Propósitos y representaciones, 7(1), 201-229. https://doi.org/10.20511/ pyr2019.v7n1.267

Jiménez, A. (2016). Pensamiento complejo y apreciación estética en la obra «Melancolía I» de Alberto Durero (tesis de maestría). Multiversidad Mundo Real Edgar Morin. Recuperado de https://multiversidadreal.edu.mx/

Leyva, J. (2009). Los presupuestos teóricos de la epistemología compleja. A parte Rei, Revista de Filosofía, (61), 1-13. Recuperado de http://serbal.pntic.mec. es/AParteRei/

Max-Neef, M. (2004). Fundamentos de la transdisciplinaridad. Valdivia: Universidad Austral de Chile. Recuperado de http://www.ecosad.org/phocadownloadpap/otrospublicaciones/max-neef-fundamentos-transdisciplinaridad.pdf

Morin, E. (2000). Por una reforma del pensamiento. Revista Magistralis, (18), 61-71. Recuperado de https://repositorio.iberopuebla.mx/bitstream/handle/20. 500.11777/495/Magistralis18-Morin.pdf?sequence $=1$ \&isAllowed $=y$

Morin, E. (2001). Introducción al pensamiento complejo. Barcelona: Editorial Gedisa.

Muller, C. (2002). Ingenio y melancolía, una lectura de Huarte de san Juan. Madrid: Biblioteca Nueva.

Noel, M. (2014). El concepto de la melancolía en Marcilio Fisino. Eikasia, Revista de Filosofia, (57), 173-186. Recuperado de https://dialnet.unirioja.es/ servlet/articulo?codigo $=4907629$

Panofsky, E. (1955). Vida y arte de Alberto Durero. Madrid. Alianza Editorial S.A.

Panofsky, E. (2018). Estudios en iconología. Nueva York: Routledge.

Pereira, J. (2010). Consideraciones básicas del pensamiento complejo de Edgar Morin, en la educación. Revista Electrónica Educare, 14(1), 67-75. https:// doi.org/10.15359/ree.14-1.6

Torrealba, R. (2009). La producción del conocimiento y el pensamiento complejo. Revista Ciencias de la Educación, 19(33), 169-182. Recuperado de http://servicio.bc.uc.edu.ve/educacion/revista/n33/art8.pdf

Velázquez, M. (2012). El método iconológico. Recuperado de https://miguelangelvelasquez.files.wordpress.com/2012/07/actividad-2-1.pdf

Viadel, R. (2003). Didáctica de la educación artística. España: Pearson. 